\title{
Undernutrition and Associated Factors Among Adolescent Girls in Damot Sore District, Southern Ethiopia
}

\author{
Degu Demissie ${ }^{1} \quad$ Amene Abebe $^{2} \quad$ Thilagavathi Thangavel $^{3}$ \\ 1.Wolaita Sodo University, college of medicine and health sciences, department of human nutrition, Wolaita \\ Sodo, Ethiopia \\ 2.Wolaita Sodo University, college of medicine and health sciences, department of public health, Wolaita Sodo, \\ Ethiopia \\ 3.Wolaita Sodo University, college of medicine and health sciences, department of human nutrition, Wolaita \\ Sodo, Ethiopia
}

\begin{abstract}
Background: Adolescents girls were given little health and nutrition attention. Focusing on adolescent girls' nutrition prior to conception is one way to break the intergenerational cycle of malnutrition. Therefore, the aim of this study was to assess the prevalence of undernutrition and associated factors among adolescent girls in rural Damot Sore District, Southern Ethiopia.

Methods: A community based cross-sectional study was conducted from February to March, 2017. Multistage sampling technique was used to select 729 adolescent girls. Structured interviewer administered questionnaire was used to collect information on different variables. Weight and height were measured by well-calibrated digital Seca scale and portable stadio-meter by trained data collectors. Descriptive statistics, bivariable and multivariable logistic regression analysis was done. Strength of association of dependent and independent variables was presented by odds ratio along with its $95 \%$ CI.

Results: The prevalence of stunting and thinness among adolescent girls were $29.6 \%(95 \% \mathrm{CI}=26.6 \%, 32.8 \%)$ and $19.5 \%(95 \% \mathrm{CI}=16.7 \%, 22.3 \%)$ respectively. Being in older adolescence period $(\mathrm{AOR}=2.06,95 \% \mathrm{CI}=1.08$, $3.92)$, mother occupation (farmer and government employee) $[(\mathrm{AOR}=2.38,95 \% \mathrm{CI}=1.31,4.33)$ and $(\mathrm{AOR}=$ $3.05,95 \% \mathrm{CI}=1.35,6.92)]$, mother education (secondary and more than secondary) $[(\mathrm{AOR}=0.53,95 \% \mathrm{CI}=0.28$, $0.98)$ and $(\mathrm{AOR}=0.25,95 \% \mathrm{CI}=0.09,0.69)]$ and household wealth index (poor) $(\mathrm{AOR}=1.94,95 \% \mathrm{CI}=1.29$, 2.92 ) were significantly associated with stunting. Father education (primary and secondary) [(AOR=0.48, $95 \% \mathrm{CI}=0.31,0.77)$ and $(\mathrm{AOR}=0.45,95 \% \mathrm{CI}=0.26,0.78)]$, mother education (primary) $(\mathrm{AOR}=0.56,95 \% \mathrm{CI}=$ $0.37,0.87)$ and meal frequency $(<2 /$ day $)(\mathrm{AOR}=1.87,95 \% \mathrm{CI}=1.12,3.13)$ were significantly associated with thinness.

Conclusion: High prevalence of stunting and thinness were observed in the study area. In older adolescence, from poor family, mother occupation and eating less meal per day were negatively associated while educated both parents was positively associated with stunting and thinness. Initiation of routine screening and implementing evidence based community nutrition programmes is needed to improve nutritional status of adolescent girls.
\end{abstract}

Key words: Adolescence, adolescent girls, Damot Sore, stunting, thinness, undernutrition

DOI: $10.7176 / \mathrm{FSQM} / 91-03$

Publication date:October $31^{\text {st }} 2019$

\section{Background}

World Health Organization (1986) defines adolescents as persons aged 10-19 years. It refers to the developmental period where a decisive transition from childhood to adulthood occurs [1]. This age group make up roughly $20 \%$ of the total world population and remarkably $84 \%$ of them are in developing countries. In Ethiopia, children and adolescent constitutes about $48 \%$ of Ethiopian population and of this about $13 \%$ are girls according to mini Ethiopian demographic and health survey 2014[2,3]. Adolescence is the second most critical period of physical growth in life cycle after first year of infancy. It is the most important period of life where growth and development are accompanied by numerous physical, physiological, behavioural and social changes. This leads to increased demand for nutrients. If not met this in turn could pose to a greater risk of undernutrition [4-6]. They can no longer merely viewed as a stage between childhood and adulthood, but is now a unique and important developmental period requiring specific programming and policy implementation. It is the future generation of any country and their nutritional needs are critical for the wellbeing of a society [7].

Inadequate diet has contributed a lot to the poor nutritional status of adolescents. Undernutrition among adolescents is a serious problem especially in developing countries [8]. It is one of the most common causes of morbidity among adolescents throughout the world. They face a series of serious nutritional challenges, which would affect this rapid growth spurt and their health as adults. Hence, the prevalence of undernutrition, particularly, among adolescents is an alarming global problem and affecting about one third of the world population $[1,7,9]$. 
In Sub-Saharan Africa, the prevalence of adolescence undernutrition was $15 \%$ to $58 \%$, which is higher relative to countries of other regions of Africa [4]. From eleven studies conducted in the developing countries, the prevalence of stunting among Kenyan adolescent school girls was $12.1 \%$ and $67.3 \%$ and $57.8 \%$ of the Nigerian adolescent boys and girls were stunted[10]. One study from Tanzania, Stunting was prevalent in $64.2 \%$ of rural adolescents[11].

Adolescent girls are the main vulnerable and neglected sector of the population especially from rural community of Ethiopia. In contrast to boys; they face intra household gender discrimination in food allocation with preference to sons, lack of opportunity during puberty and posed to heavy work burdens and are more prone to nutritional problems. Moreover, their restriction in freedom, have compounded prevalence of the problem in girls to larger extent [12-14]. National nutrition baseline survey conducted in Ethiopia reported that, girls in rural areas more likely to be stunted with the prevalence of $23 \%$ and $14 \%$ of adolescent girls had a low body mass index for age (thin) [15].

Poor nutritional status among adolescents is an important determinant of poor health outcomes. Poorly nourished women give birth to poorly nourished babies who are then more likely to become undernourished. Girls who are stunted and later become pregnant are likely to give birth to small-for-gestational age (low birth weight baby), which indicates Undernourished adolescent girls are more likely to have undernourished mothers and that they are more likely to have been undernourished in early childhood, will have undernourished offspring in the future, thus transmitting under nutrition to future generation[16-19]. Short stature resulting from chronic undernutrition is associated with reduced lean body mass and deficiencies in muscular strength and working capacity. And Furthermore, malnourished adolescents are sub-optimally productive during adulthood, leading to reduced economic potential and perpetuates the cycle of poverty. Hence, improving adolescent girls' nutrition and health prior to conception is one way to break the intergenerational cycle of malnutrition otherwise, the vicious cycle of malnutrition will continue and resulting in more and more severe consequences [19-22].

Until recently, there are only very few studies have been carried out in this age group and little is known about their nutritional status from developing world especially those adolescent girls residing in rural communities of Ethiopia. Most of the extant literatures indicate that much has been known regarding the nutritional status of in school and pregnant adolescent girls. However, those who are not attending schools and non-pregnant adolescent girls were not given adequate attention they deserve and their health has been neglected. Moreover, adolescent girl's nutritional status was not included in the national health and nutrition surveys, which is indicative of lack or low interest of policy makers' regarding the issue [23-25]. However; this approach ignores the fact that many health problems later in life can be improved by adapting nutrition intervention and healthy life style during adolescence $[5,26]$. Therefore, this study aimed to fill such a gap in assessing the prevalence of undernutrition and associated factors among adolescent girls in rural Damot Sore District, Southern Ethiopia.

\section{Methods and materials}

\section{Study setting, design and period}

This study was conducted in Damot Sore Woreda (administrative stage) which is located at $320 \mathrm{~km}$ away from Addis Ababa to the South and $17 \mathrm{~km}$ away from Sodo Town in the Westren direction. The Woreda has 21 kebeles (the smallest administrative unit in Ethiopia) with different climatic zones and rural urban living residences. Among 22 kebeles, 3 are urban whereas 18 of them are rural. Data were collected exclusively from rural kebeles. According to the Woreda health office 2016 report, Damot Sore Woreda has the total population of 128,184 and of these; number of households with adolescent girls were estimated to be 19,228[3, 27]. A community based cross-sectional study design was employed among households with adolescent girls aged 1019 years old. The source population for the current study was adolescent girls residing in the Damot Sore district and all households with adolescent girls aged 10-19 years in selected kebeles of Damot Sore district were the study population. This study was conducted from January to February 2017, giving consideration to food surplus season of the year in Ethiopia.

\section{Sample size determination and sampling technique}

The sample size for the study was calculated using single population proportion formula. The assumptions considered to calculate the sample size include $95 \%$ confidence level of significance $\left(Z_{\alpha / 2=1.96)}\right.$, margin of error $5 \%$, design effect of 2 and the prevalence of stunting of $31.5 \%$ was taken from a community based cross sectional study conducted among adolescent girls in the Amhara region, northern Ethiopia [30] and 10\% (66 participants) for non-response, the final samples size was 729 households with adolescent girls.

A multistage stage sampling technique was employed. In the first stage, from 18 rural kebeles, seven kebeles were selected by simple random sampling technique or lottery method. According to the size of adolescent girls' population, sample size was distributed to each kebele proportionally. In the second stage, study participants (households with at least one adolescent girl) were selected using systematic sampling technique by 
preparing sampling interval $(\mathrm{N} / \mathrm{n}=11)$ from the sampling frame obtained from the list of households with adolescent girls in each kebele family folder (family registration book) or community health information system (CHIS). The first household was selected by choosing one number out of the sampling interval randomly by lottery method and every $11^{\text {th }}$ house hold was included until the required sample size was achieved. The direction to start at the first household was selected randomly. In cases where there are two or more adolescent girls in the same household, one of them was selected randomly by lottery method. In other case when there is no adolescent girl in the selected household, the adjacent/next household was selected. Those adolescent girls aged 10-19 years who were critically ill and physically disabled for anthropometric measurements were excluded from the study.

\section{Data collection procedures and instruments}

For data collection, face to face, structured interviewer administered questionnaire and anthropometric measurements were used. The questionnaire consisting of socio-demographic and economic, food/dietary intake pattern, reproductive health, morbidity status and information regarding other associated factors that are extracted from different literatures were used as data collection tool. The questionnaire was initially prepared in English and translated to local language (Wolaitigna) and then translated back to English to check the consistency by language experts. A total of 14 diploma holder female nurses who were fluent speakers of the local language were recruited and collected the data, considering prior experience of participation in anthropometric data collection and two public health officers supervised the data collection. The data collectors were trained on the data collection procedures, the context of specific questions across the questionnaire and anthropometric measurement procedures.

Anthropometric assessment constitutes weight and height measurements. Weight was measured using a well-calibrated, portable digital seca scale to the nearest $0.1 \mathrm{~kg}$. Height was measured using a portable stadiometer, which consisted of an anthropometer with a simple triangular headboard to the nearest $0.1 \mathrm{~cm}$. The participants were measured for weight and height by taking off shoes, heavy clothes and mobile from the pocket, and by standing upright/straight where their head held erect and their shoulder blade, buttocks, back of the head and heel touching the scale with knees and arms hanging naturally by the sides and by standing on the foot mark on scale such that the external auditory meatus and the lower boarder of the eye were in one horizontal plane (Frankfurt plane) respectively according to the WHO recommendations [28]. WHO Anthroplus computer program was used to assess nutritional status in terms of stunting and thinness of adolescent girls. The anthropometric measurements were converted in to height-for-age $\mathrm{z}$ scores and BMI-for-age $\mathrm{z}$ scores and compared to the new 2007 WHO reference data for 5-19 years [28, 29]. Stunting and thinness were defined as height-for-age and body mass index-for-age $<-2 \mathrm{Z}$-scores of the references according to predetermined CDC cut off points and WHO reference data of 5-19 years population .

\section{Data quality control and standardization}

Questionnaire was first prepared in English and translated to wolaitigna language by language experts then back translated to English to maintain its consistency. Both data collectors and supervisors were trained by principal investigator for three days on the objective, relevance of the study, the operation of the weight and height measurement scales data collecting and interviewing approach, how to select adolescents from the household, respondent's right, proper filling of questionnaire and data recording. The questionnaire was Pre-tested on 5\% of the sample size from two Kebeles (Demba Zamine and Shakisho) which were not selected for the actual study. Based on the pre-test, validity and reliability of the measurement was checked, questions that posed difficulty were revised, edited, and those found to be unclear or confusing were removed.

To assure the accuracy of anthropometric measurement, standardization test was done in $10 \%$ (73) of adolescents before the actual survey and systematized based on the result. To do standardization test, a seventy three adolescents were selected and principal investigator measured their height and weight twice as an expert measurement. Then the two anthropometric data collectors measured the same adolescents twice with sometime interval. The anthropometric data then entered in to ENA SMART software to see relative Technical Error of Measurement (TEM). The TEM was found to be in acceptable range.

Two different measurements were taken for the height and weight by two different measurement takers for every study subjects so that the average of the two was considered for the analysis when two measurements differ by one unit. This would help in reducing the occurrence of measurement errors by single individual measurement to avoid inter and intra-observer error[28]. To improve the quality of data, the data collectors were closely supervised. Completeness, accuracy and consistency of the collected data were checked on daily bases during data collection by the supervisors and principal investigator. Any filled questionnaire that has a difficulty to understand was rejected from the study. The principal investigator was responsible for co-ordination and supervision of the overall data collection process. 


\section{Data processing and analysis}

Before data entry and cleaning, the data were checked manually for completeness and consistency. Data were coded and entered in to Epi-Data version 3.1 and exported to SPSS version 20 for analysis. Anthropometric data were entered and analysed using Anthroplus software. Principal component analysis (PCA) was used to generate wealth index. Based on PCA, the results of household wealth status/index was converted into tertiles and categorized into higher/rich, medium and lower/poor tertiles. Descriptive statistics using frequency with proportions, mean, standard deviations, and correlation were used to present study results. All continuous variables were checked for normality by using Kolmogorov-Smirov test at p-value $>0.05$. When normality was not be maintained (age, height and weight), in place of mean median was considered. Bivariate and multivariate logistic regression was done to assess the association between adolescent undernutrition in terms of stunting and thinness. Before inclusion of predictor variables, Multicollinearity was also checked among selected variables by using cut-off point of $\mathrm{VIF}<10$ and tolerance test greater than 0.1 . Hosmer and Lemeshow goodness of fit test was used to assess fitness of the model during multivariable analysis at a value of $>0.05$. Strength of association was measured using both crude and adjusted odds ratios along with 95\% confidence interval were reported among study variables. P-value less than 5\% (0.05) was considered to declare statistical significance of the dependent variable with independent variables.

\section{Operational Definition of Terms}

Anthropometry: The technique that deals with the measurements of the size, weight and Proportions of the human body

Adolescents: individuals in the age group of 10-19 years

Household: Means a group of people, each with different abilities and needs, who live together most of the time and who sleep under the same roof, take meals together at least four days in a week and contribute to a common economy.

Kebele: The smallest administrative unit in the Ethiopian administrative stages

Stunting: Height-for-age z-scores below minus two standard deviations ( -2 SD) from the median of the new WHO reference population

Thinness: BMI-for- age Z-scores less than -2 Standard deviation from the median of the new WHO 2007 reference population

Wealth Index: Two or more assets owned by a household like farm land, farm instruments, livestock ownership and durable goods(motor cycle, bicycle, mobile phones, radio, chairs, tables, television, watch, jewellery and housing quality used for floor, wall\& roof) etc. it is the an indicator of household living standard.

\section{Ethical clearance}

Ethical clearance was obtained from the Institutional Research Ethics Review Committee of Wolaita Sodo University. Additionally, permission to conduct the study in the local area was obtained from kebele leaders. All selected participants were informed about the objective of the study and data were collected after getting informed verbal consent from the participants. For respondents less than 18 years old, informed oral consent was obtained from their parents or caregivers and assents from the girls. For the 19 years old adolescents, consent was obtained from the adolescents themselves. To ensure confidentiality of participants, participant codes were used thereby; the names of the participants and any participants' identifiers were not written on the questionnaire. The respondents were assured they have the right to refuse or decline from the study at any time, not to answer the question they do not want to answer and refusing to participate on the study could not bring any effect on them.

\section{Results}

\section{Socio-demographic characteristics of study participants}

A total of 719 adolescent girls were enrolled in the study, making the response rate of $98.6 \%$. Of the study subjects, $435(60.5 \%)$ were younger/early adolescent girls within the age group of 10-14 years and the median age of respondents was 14years with the Inter Quartile Range of being 3 years. As to religion and ethnicity of respondents, more than half, 374(52.0\%) and almost all, 694(96.5\%) of the respondents were protestant in religion and Wolaita in ethnicity respectively. As to the family of respondents, Over half of the respondents, $437(60.8 \%)$ were from large family size (>five members). The occupational status of study participants' family showed that, $355(49.4 \%)$ of their fathers and $317(44.0 \%)$ of their mothers were farmers and house wives respectively. The educational background of their parents revealed that, two hundred eighty two (39.2\%) of their fathers and 311(43.3\%) of their mothers attended primary education. Regarding household wealth index level, two hundred forty three $(33.8 \%)$ of the respondents were from poor families.

Majority, 487(67.7\%) of the respondents' family had dry pit latrine with slab. Almost all, 704(97.9\%) of the respondents, used water from safe source (tape and spring water) for drinking purpose. As to meal frequency 
of respondents, more than half, $450(62.6 \%)$ and around $24.3 \%$ have consumed their regular meal three times a day. Almost all, 701(97.5\%) of the respondents had no history of skipping their regular meal. Majority, 708(98.5\%) of the study participants had little/no household hunger due to shortage of food (Table-1).

Table 1: Socio-demographic and economic characteristics among adolescent girls in Damot Sore Woreda, Southern Ethiopia, 2017

\begin{tabular}{|c|c|c|c|}
\hline Variables & Categories & Frequency & Percent \\
\hline \multirow[t]{2}{*}{ Girls age } & 10-14 years & 435 & 60.5 \\
\hline & $15-19$ years & 284 & 39.5 \\
\hline \multirow[t]{4}{*}{ Religion } & Protestant & 374 & 52.0 \\
\hline & Orthodox & 178 & 24.7 \\
\hline & Apostolic & 117 & 16.3 \\
\hline & Catholic & 50 & 7.0 \\
\hline \multirow[t]{2}{*}{ Ethnicity } & Wolaita & 694 & 96.5 \\
\hline & Others $^{\mathrm{a}}$ & 25 & 3.5 \\
\hline \multirow[t]{2}{*}{ Family size } & $\leq 5$ & 282 & 39.2 \\
\hline & $>5$ & 437 & 60.8 \\
\hline \multirow[t]{5}{*}{ Father's occupation } & Farmer & 355 & 49.4 \\
\hline & Merchant & 263 & 36.6 \\
\hline & Daily labourer & 42 & 5.8 \\
\hline & Government employee & 40 & 5.6 \\
\hline & other $^{\mathrm{b}}$ & 19 & 2.6 \\
\hline \multirow[t]{5}{*}{ Mother's occupation } & House wife & 317 & 44.0 \\
\hline & Merchant & 286 & 39.8 \\
\hline & Farmer & 66 & 9.2 \\
\hline & Government employee & 32 & 4.5 \\
\hline & other ${ }^{\mathrm{c}}$ & 18 & 2.5 \\
\hline \multirow[t]{4}{*}{ Father's education } & No formal education & 191 & 26.6 \\
\hline & Primary education & 282 & 39.2 \\
\hline & Secondary education & 187 & 26.0 \\
\hline & More than secondary education & 59 & 8.2 \\
\hline \multirow[t]{4}{*}{ Mother's education } & No formal education & 290 & 40.3 \\
\hline & Primary education & 311 & 43.3 \\
\hline & Secondary education & 83 & 11.5 \\
\hline & More than secondary education & 35 & 4.9 \\
\hline \multirow[t]{3}{*}{ Wealth index } & Rich & 260 & 36.2 \\
\hline & Medium & 216 & 30.0 \\
\hline & Poor & 243 & 33.8 \\
\hline \multirow[t]{3}{*}{ Source/origin of food } & Own product \& market purchase & 449 & 62.4 \\
\hline & Own product & 205 & 28.5 \\
\hline & Market purchase & 65 & 9.1 \\
\hline \multirow[t]{3}{*}{ Frequency of meals per day } & Two times & 94 & 13.1 \\
\hline & Three times & 450 & 62.6 \\
\hline & Four times & 175 & 24.3 \\
\hline \multirow[t]{2}{*}{ Regular meals skipped } & No & 701 & 97.5 \\
\hline & Yes & 18 & 2.5 \\
\hline \multirow[t]{2}{*}{ Episode of household hunger } & No/little & 708 & 98.5 \\
\hline & One times & 11 & 1.5 \\
\hline \multirow[t]{2}{*}{ Type of latrine } & Pit latrine with slab & 487 & 67.7 \\
\hline & Pit latrine without slab/open pit & 232 & 32.3 \\
\hline \multirow[t]{3}{*}{ Source of drinking water } & Tape water & 632 & 87.9 \\
\hline & Spring water & 72 & 10.0 \\
\hline & Others* & 15 & 2.1 \\
\hline \multirow[t]{3}{*}{ Hand washing prior to meal } & $\leq 2$ times & 99 & 13.8 \\
\hline & 3 times & 552 & 76.7 \\
\hline & $\geq 4$ times & 68 & 9.5 \\
\hline \multirow[t]{3}{*}{ Soap using when washing hands } & $\leq 2$ times & 14 & 2.0 \\
\hline & 3 times & 495 & 68.8 \\
\hline & $\geq 4$ times & 210 & 29.2 \\
\hline
\end{tabular}

${ }^{a}$ Dawuro, Gamo and Gofa, ${ }^{b}$ pastor, student, self-employee ${ }^{c}$ private employee, student 


\section{Nutritional status of adolescent girls}

The median height and weight of the respondents were $150 \mathrm{~cm}$ and $42 \mathrm{~kg}$ respectively. The mean $\pm \mathrm{SD}$ BAZ and HAZ were $-0.41 \pm 1.0$ and $-0.81 \pm 0.9$ respectively. Nutritional status of respondents was determined by using CDC cut-off points and 2007 WHO growth reference classification for BMI-for-age and height-for-age. According to the result, $2(0.3 \%)$ of the subjects were severely thin with BMI-for-age $\mathrm{z}$-scores $<-3 \mathrm{SD}$ while 138 $(19.2 \%)$ were thin with BMI-for-age $z$-scores $<-2$ SD). As to stunting, 4(0.5\%) of the respondents were severely stunted with HAZ<-3SD and 209(29.1\%) were stunted with $\mathrm{HAZ}<-2$ SD respectively.

The overall prevalence of stunting (low height-for-age) and thinness (low body mass index-for-age) among adolescent girls were $29.6 \%$ (95\% CI; 26.6\%-32.8\%) and 19.5\% (95\% CI; 16.7\%-22.3\%) respectively (Figure-5). Both Stunting and thinness were more prevalent among older/late adolescent girls than younger/early adolescent girls $35.6 \%$ Vs $25.7 \%$ and $21.8 \%$ Vs $17.9 \%$ respectively. This indicating that, both stunting and thinness were increasing with the increasing age of girls especially during older adolescence period. Sixty one of the study participants were both stunted as well as thin. From the stunted girls, 21(43.8\%) had malaria and $13(56.5 \%)$ had diarrhoea whereas from thin adolescents, 29(60.4\%) had malaria and 21(91.3\%) had diarrhoea.

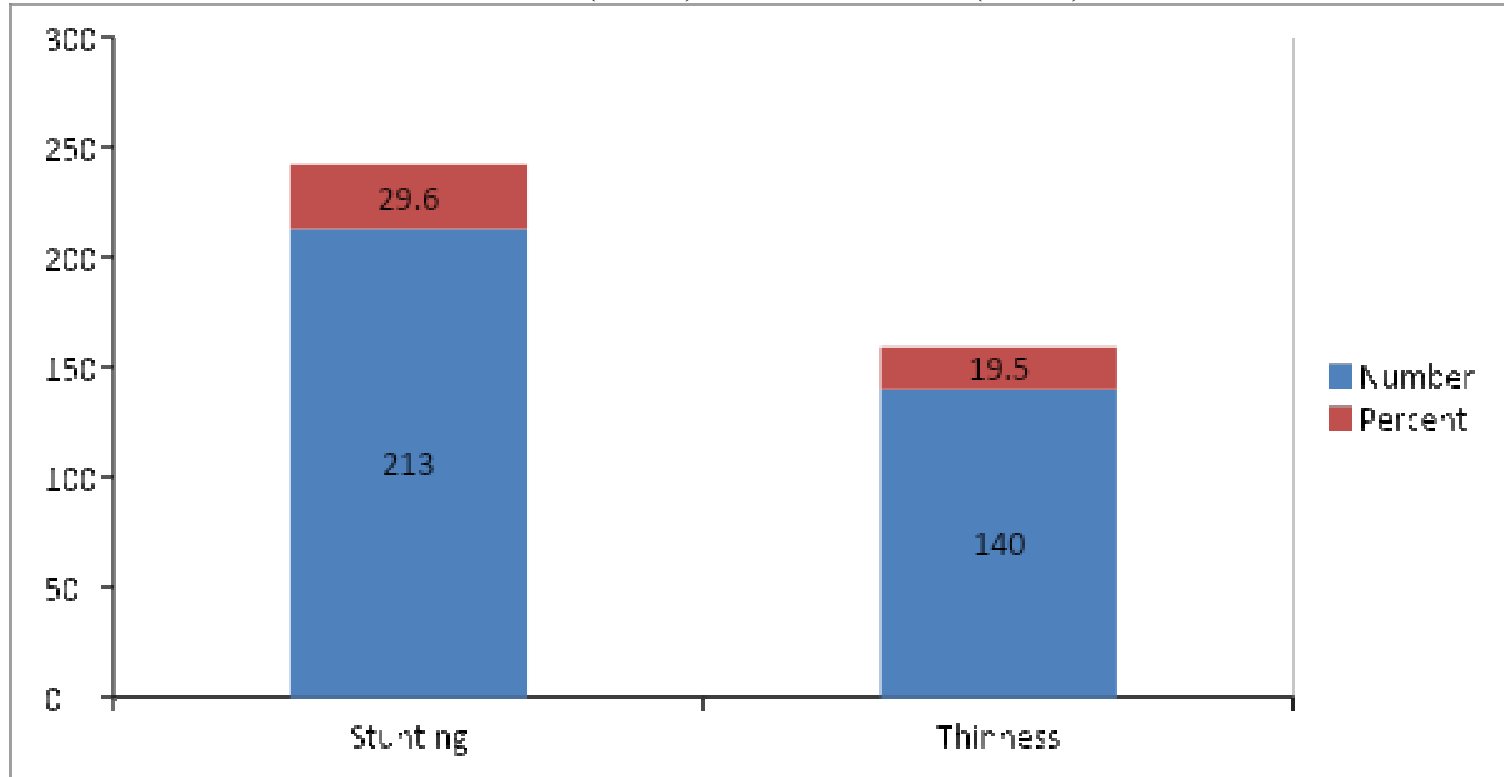

Figure 1: Nutritional status among adolescent girls in Damot Sore Woreda, Southern Ethiopia, 2017.

\section{Factors associated with stunting among adolescent girls}

In a bivariate logistic regression model variables that were significantly associated $(\mathrm{p}<0.05)$ with stunting were , being in older adolescent period, mother occupation, mother educational status, wealth index and mothers' age. Other variables such as father occupation, father education, family size, frequency of meal per day, using soap while washing hands and girls who started menarche were found to be associated with stunting at $p$-value $<0.25$. The multivariable analysis was performed for variables showed statistically significant association with stunting at bivariate level. However, in multivariable logistic regression, only being in older adolescent age, mother occupation; mother educational status and wealth index were found to be statistically significantly associated with stunting.

The study findings show that, older adolescent girls have 2 times higher odds of developing stunting as compared to their counter parts $(\mathrm{AOR}=2.06,95 \% \mathrm{CI}=1.08,3.92)$. Adolescent girls whose mothers' occupation being farmer were 2.4 times $(\mathrm{AOR}=2.38,95 \% \mathrm{CI}=1.31,4.33)$ more likely to be stunted whereas those girls whose mothers' occupation being government employee were 3 times ( $\mathrm{AOR}=3.05,95 \% \mathrm{CI}=1.35,6.92$ ) more likely stunted as compared to those girls' mothers' occupation being housewife. Adolescent girls from educated mothers were less likely prone to stunting when compared to those from non-educated one. Adolescent girls whose mothers had secondary education have $47.0 \%(\mathrm{AOR}=0.53,95 \% \mathrm{CI}=0.28,0.98)$ lower odds of developing stunting while those girls whose mothers attended more than secondary education have $75.0 \%(\mathrm{AOR}=0.25$, $95 \% \mathrm{CI}=0.09,0.69)$ lower odds to develop stunting as compared to mothers who had no formal education. The result also revealed that there was statistically significant association between household wealth index and adolescents' nutritional status. Those adolescent girls whose household wealth tertile was lower/poor were 2 times more likely to be stunted than adolescent girls whose household wealth tertile was higher/rich $(\mathrm{AOR}=1.94$, $95 \% \mathrm{CI}=1.29,2.92)($ Table-5). 
Table 2: Factors associated with stunting during bivariable and multivariable analysis among adolescent girls in Damot Sore Woreda, Southern Ethiopia, 2017

\begin{tabular}{|c|c|c|c|c|}
\hline \multirow[t]{2}{*}{ Variables } & \multicolumn{2}{|c|}{ Stunting } & \multirow[t]{2}{*}{$\operatorname{COR}(95 \% \mathrm{CI})$} & \multirow[t]{2}{*}{$\operatorname{AOR}(95 \% \mathrm{CI})$} \\
\hline & Yes $(\mathrm{N}, \%)$ & No $(N, \%)$ & & \\
\hline \multicolumn{5}{|l|}{ Girl's age } \\
\hline $10-14$ years & $112(25.7)$ & $323(74.3)$ & 1 & 1 \\
\hline $15-19$ years & $101(35.6)$ & $183(64.4)$ & $1.60(1.15-2.20)^{* *}$ & $2.06(1.08-3.92)^{*}$ \\
\hline \multicolumn{5}{|l|}{ Mother's age } \\
\hline $35-49$ years & $147(28.8)$ & $364(71.2)$ & 1 & 1 \\
\hline 20-34 years & $21(23.3)$ & $69(76.7)$ & $0.75(0.45-1.27)$ & $0.71(0.40-1.24)$ \\
\hline$\geq 50$ years & $45(38.1)$ & $73(61.9)$ & $1.53(1.01-2.32)^{*}$ & $1.26(0.80-1.98)$ \\
\hline \multicolumn{5}{|l|}{ Family size } \\
\hline$\leq 5$ & $91(32.3)$ & 191(67.7) & $1.23(0.89-1.70)$ & $1.30(0.91-1.86)$ \\
\hline$>5$ & $122(27.9)$ & $315(72.1)$ & 1 & 1 \\
\hline \multicolumn{5}{|l|}{ Father's occupation } \\
\hline Farmer & $93(26.2)$ & $262(73.8)$ & 1 & 1 \\
\hline Merchant & $86(32.7)$ & $177(67.3)$ & $1.37(0.96-1.94)$ & $1.48(0.99-2.20)$ \\
\hline Daily labourer & $12(28.6)$ & $30(71.4)$ & $1.13(0.55-2.30)$ & $1.05(0.49-2.27)$ \\
\hline Government employee & $14(35.0)$ & $26(65.0)$ & $1.52(0.76-3.03)$ & $1.86(0.60-5.79)$ \\
\hline Other & $8(42.1)$ & $11(57.9)$ & $2.05(0.80-5.25)$ & $1.62(0.56-4.61)$ \\
\hline \multicolumn{5}{|l|}{ Mother's occupation } \\
\hline House wife & $90(28.4)$ & $227(71.6)$ & 1 & 1 \\
\hline Merchant & $70(24.5)$ & $216(75.5)$ & $0.82(0.57-1.18)$ & $0.78(0.53-1.17)$ \\
\hline Farmer & $30(45.5)$ & $36(54.5)$ & $2.10(1.22-3.62)^{* *}$ & $2.38(1.31-4.33)^{* *}$ \\
\hline Government employee & $17(53.1)$ & $15(46.9)$ & $2.86(1.37-5.97) * *$ & $3.05(1.35-6.92)^{* *}$ \\
\hline Other & $6(33.3)$ & $12(66.7)$ & $1.26(0.46-3.46)$ & $1.42(0.49-4.11)$ \\
\hline \multicolumn{5}{|l|}{ Father's education } \\
\hline No formal education & $58(30.4)$ & $133(69.6)$ & 1 & 1 \\
\hline Primary education & $69(24.5)$ & $213(75.5)$ & $0.74(0.49-1.12)$ & $0.64(0.41-1.03)$ \\
\hline Secondary education & $68(36.4)$ & $119(63.6)$ & $1.31(0.85-2.01)$ & $1.19(0.73-1.93)$ \\
\hline More than secondary education & $18(30.5)$ & $41(69.5)$ & $1.01(0.53-1.89)$ & $0.69(0.24-1.98)$ \\
\hline \multicolumn{5}{|l|}{ Mother's education } \\
\hline No formal education & $101(34.8)$ & $189(65.2)$ & 1 & 1 \\
\hline Primary education & $83(26.7)$ & $228(73.3)$ & $0.68(0.48-0.96)^{*}$ & $0.69(0.47-1.02)$ \\
\hline Secondary education & $23(27.7)$ & $60(72.3)$ & $0.72(0.42-1.23)$ & $0.53(0.28-0.98)^{*}$ \\
\hline More than secondary education & $6(17.1)$ & $29(82.9)$ & $0.38(0.16-0.96)^{*}$ & $0.25(0.09-0.69)^{* *}$ \\
\hline \multicolumn{5}{|l|}{ Number of meals per day } \\
\hline Three times & $130(28.9)$ & $320(71.1)$ & 1 & 1 \\
\hline$\geq$ Four times & $49(28.0)$ & $126(72.0)$ & $0.96(0.65-1.41)$ & $1.08(0.70-1.67)$ \\
\hline$\leq$ Two times & $34(36.2)$ & $60(63.8)$ & $1.39(0.87-2.23)$ & $1.52(0.91-2.53)$ \\
\hline \multicolumn{5}{|l|}{ Soap using when washing hands } \\
\hline$\leq$ Two times & $6(42.9)$ & $8(57.1)$ & $2.28(0.76-6.87)$ & $2.47(0.73-8.43)$ \\
\hline Three times & $155(31.3)$ & $340(68.7)$ & $1.38(0.96-1.99)$ & $1.36(0.91-2.02)$ \\
\hline$\geq$ Four times & $52(24.8)$ & $158(75.2)$ & 1 & 1 \\
\hline \multicolumn{5}{|l|}{ Started menarche } \\
\hline No & $102(27.1)$ & $275(72.9)$ & 1 & 1 \\
\hline Yes & $111(32.5)$ & $231(67.5)$ & $1.29(0.94-1.78)$ & $0.72(0.38-1.35)$ \\
\hline \multicolumn{5}{|l|}{ Wealth index } \\
\hline Higher/rich & $65(25.0)$ & $195(75.0)$ & 1 & 1 \\
\hline Medium & $50(23.1)$ & $166(76.9)$ & $0.90(0.59-1.38)$ & $0.86(0.55-1.35)$ \\
\hline Lower/poor & $98(40.3)$ & $145(59.7)$ & $\begin{array}{l}2.03(1.38- \\
2.96)^{* * *}\end{array}$ & $1.94(1.29-2.92)^{* *}$ \\
\hline
\end{tabular}

$*$ P-value $<0.05, * * p$-value $<0.01, * * * p$-value $\leq 0.001$

\section{Factors associated with thinness among adolescent girls}

During bivariable analysis, fathers' education, mothers' education, number of meals being eaten per day and using soap when washing hands per day were associated with thinness at p-value $<0.05$. But variables like girls' age, family size, girls who started menarche, and wealth index were associated with being thin at $\mathrm{p}$-value $<0.25$. However, most variables lost their significance in the multivariable model and only fathers' education, mothers' 
education and frequency of meal per day were found to be statistically significantly associated with being thin. Adolescent girls whose fathers' education level being primary were $52.0 \%(\mathrm{AOR}=0.48,95 \% \mathrm{CI}=0.31,0.77)$ less likely thin while girls whose fathers' education being secondary level were $55.0 \%(\mathrm{AOR}=0.45,95 \% \mathrm{CI}=$ $0.26,0.78)$ less likely thin as compared to those girls whose fathers had no formal education. Similarly adolescent girls whose mothers' education being primary level were $44.0 \%$ less likely thin when compared to those girls whose mothers had no formal education $(\mathrm{AOR}=0.56,95 \% \mathrm{CI}=0.37,0.87)$. Those female adolescents who usually eat two meals and less per day were 1.8 times $(\mathrm{AOR}=1.87,95 \% \mathrm{CI}=1.12,3.13)$ more likely thin as compared to those who usually eat three meals per day (Table-6).

Table 3: Factors associated with thinness during bivariable and multivariable analysis among adolescent girls in Damot Sore Woreda, Southern Ethiopia, 2017

\begin{tabular}{|c|c|c|c|c|}
\hline \multirow[t]{2}{*}{ Variables } & \multicolumn{2}{|c|}{ Thinness } & \multirow[t]{2}{*}{$\operatorname{COR}(95 \% \mathrm{CI})$} & \multirow[t]{2}{*}{$\operatorname{AOR}(95 \% \mathrm{CI})$} \\
\hline & Yes $(\mathrm{N}, \%)$ & $\mathrm{NO}(\mathrm{N}, \%)$ & & \\
\hline \multicolumn{5}{|l|}{ Girl's age } \\
\hline $10-14$ years & $78(17.9)$ & $357(82.1)$ & 1 & 1 \\
\hline $15-19$ years & $62(21.8)$ & $222(78.2)$ & $1.28(0.88-1.86)$ & $1.08(0.56-2.07)$ \\
\hline \multicolumn{5}{|l|}{ Family size } \\
\hline$\leq 5$ & $64(22.7)$ & $218(77.3)$ & $1.39(0.96-2.02)$ & $1.38(0.94-2.06)$ \\
\hline$>5$ & $76(17.4)$ & $361(82.6)$ & 1 & 1 \\
\hline \multicolumn{5}{|l|}{ Father's education } \\
\hline No formal education & $55(28.8)$ & $136(71.2)$ & 1 & 1 \\
\hline Primary education & $47(16.7)$ & $235(83.3)$ & $0.49(0.32-0.77)^{* *}$ & $0.48(0.31-0.77)^{* *}$ \\
\hline Secondary education & $27(14.4)$ & $160(85.6)$ & $0.42(0.25-0.69)^{* *}$ & $0.45(0.26-0.78)^{* *}$ \\
\hline More than secondary & $11(18.6)$ & $48(81.4)$ & $0.57(0.27-1.17)$ & $0.73(0.33-1.60)$ \\
\hline \multicolumn{5}{|l|}{ Mother's education } \\
\hline No formal education & $73(25.2)$ & $217(74.8)$ & 1 & 1 \\
\hline Primary education & $46(14.8)$ & $265(85.2)$ & $0.52(0.34-0.78)^{* *}$ & $0.56(0.37-0.87)^{* *}$ \\
\hline Secondary education & $13(15.7)$ & $70(84.3)$ & $0.55(0.29-1.06)$ & $0.58(0.29-1.18)$ \\
\hline More than secondary & $8(22.9)$ & $27(77.1)$ & $0.88(0.38-2.03)$ & $0.85(0.35-2.05)$ \\
\hline \multicolumn{5}{|c|}{ Number of meals per day } \\
\hline Three times & $84(18.7)$ & $366(81.3)$ & 1 & 1 \\
\hline$\geq$ Four times & $25(14.3)$ & $150(85.7)$ & $0.73(0.45-1.18)$ & $0.72(0.43-1.19)$ \\
\hline$\leq$ Two times & $31(33.0)$ & $63(67.0)$ & $2.14(1.31-3.50)^{* *}$ & $1.87(1.12-3.13)^{*}$ \\
\hline \multicolumn{5}{|c|}{ Soap using when washing hands } \\
\hline$\leq$ Two times & $2(14.3)$ & $12(85.7)$ & $1.00(0.21-4.69)$ & $0.78(0.15-3.99)$ \\
\hline Three times & $108(21.8)$ & $387(78.2)$ & $1.67(1.07-2.60)^{*}$ & $1.52(0.95-2.41)$ \\
\hline$\geq$ Four times & $30(14.3)$ & $180(85.7)$ & 1 & 1 \\
\hline \multicolumn{5}{|l|}{ Started menarche } \\
\hline No & $63(16.7)$ & $314(83.3)$ & 1 & 1 \\
\hline Yes & $77(22.5)$ & $265(77.5)$ & $1.45(0.99-2.09)$ & $1.46(0.77-2.77)$ \\
\hline \multicolumn{5}{|l|}{ Wealth index } \\
\hline Rich & $46(17.7)$ & $214(82.3)$ & 1 & 1 \\
\hline Medium & $37(17.1)$ & $179(82.9)$ & $0.96(0.59-1.55)$ & $0.92(0.56-1.52)$ \\
\hline Poor & $57(23.5)$ & $186(76.5)$ & $1.43(.92-2.20)$ & $1.25(0.79-1.98)$ \\
\hline
\end{tabular}

\section{DISCUSSION}

This study has attempted to determine the prevalence and factors associated with stunting and thinness among rural adolescent girls. The results of current study indicated that, the prevalence of stunting and thinness were $29.6 \%$ and $19.5 \%$ respectively. The study findings also revealed that older adolescent girls, mothers' education, mothers' occupation and wealth index were statistically significantly associated with stunting while fathers' education, mothers' education and frequency of meal being per day were found to be significantly associated with thinness.

The prevalence of stunting 29.6\%, was in line with the study conducted in Amhara region which was $31.5 \%$ and the studies conducted in rural Varanasi, in Kathmandu, in rural Kolar district and in rural area of central India which were $26.6 \%, 32 \%, 32.2 \%$ and $30.4 \%$ respectively[23, 30-33]. However, the prevalence was higher than the studies conducted in Babile District, Eastern Ethiopia, in Addis Ababa Ethiopia, in Adowa town, northern Ethiopia, in Adama city, central Ethiopia and in urban areas of northern Tigray which were 15\%, 7.2\%, $12.2 \%, 15.6 \%$, and $21.2 \%$ respectively $[1,2,19,22,34]$.

The variation in the results of different studies might be due to, this study represents the population 
exclusively from the rural setup, whereas other studies represented the population from the urban setup as well in which there is an improvement in socio-demographic and socio-economic condition in urban setting. Another possible explanation might be due to the study setting in which those studies were conducted in institution/school based while the current study was conducted in the community setting. The other possible explanation for the high prevalence could be attributed to the nature of stunting, which indicates long term cumulative inadequacy of nutrition that remained uninterrupted throughout the adolescent life and suggests nutritional deprivation in early childhood. Hence, adolescents were more affected by stunting despite improving conditions over time now days.

The prevalence of thinness $19.5 \%$, was goes in line with a study conducted in Adwa, a study conducted in Wukro, northern Ethiopia, a study conducted in Babile district, eastern Ethiopia and a study conducted in Rawalpindi, India which were $21.4 \%, 21.6 \%, 21.6 \%$ and $20 \%[2,19,22,35]$. However, the prevalence in the current study was much lower than studies conducted in eastern Tigray which was 33.7\%[4], a study conducted in four zones (central, eastern, north-western and southern zones) of Tigray, northern Ethiopia which was $58.3 \%[20]$ and studies conducted in different areas of India which were $25.7 \%, 28.2 \%, 43.5 \%$ and $48.0 \%$ respectively[13, 23, 32, 36, 37]. As thinness is an indicator of acute undernutrition, this difference might be explained in terms of the current there improvements in nutrition, health and socio-economic status among study participants. The other justification may be the impact of the current commitment of the Ethiopian government for the improvement nutritional conditions.

However, the above finding of this study contradicts with the study finding of Mekelle city, a study finding of Amhara region, a study finding in Haryana district of India and a study finding in Kathmandu, Nepal, which were $14 \%, 13.6 \%, 13 \%$ and $9.5 \%$ respectively $[30,33,38,39]$. The variation in prevalence could be explained in socioeconomic and urban-rural difference between the study subjects and settings. In addition, as most of the thin girls had an attack of illness (diarrhea, malaria and pneumonia). This might be contributed to being thin as a recent episode of illness causing loss of weight and resulting into thinness, even though disease status has no statistically significant association in the current study.

When compared between younger/early and older/late adolescent girls, the prevalence of stunting was higher in older female adolescents than in younger ones $(35.6 \% \mathrm{Vs} 25.7 \%)$. This study identified that older adolescent girls were 2 times more likely to be stunted than their counter parts. The finding is consistent with other studies conducted in different areas such as in meiso, Somali region, in Garhwalbin, in Tamilnadu and Kathmandu India respectively [13, 24, 33, 37]. This might be due to poor/inadequate nutrient intake despite increased requirement during adolescent girls' faster growth period. Another possible explanation might be due to this is a vulnerable period in girls as they will then be approaching the marriageable age and would be expected to be pregnant and deliver babies which could explain the fact that the prevalence of stunting increases as the age of the girls increases.

The study identified that those adolescent girls whose mothers working outside home were more likely to be stunted than those who do not work outside home/house wife. Adolescent girls whose mothers' occupation being farmer and government employee were 2.4 times and 3 times more likely to be stunted than those adolescent girls whose mothers' being house wife. This finding is in agreement with studies conducted in kersa district of eastern Ethiopia and in west Bengal India[17, 40]. This might be explained by a reduced time of working mothers to care for their children at early childhood which in turn might affect the feeding practice that adversely affects the linear growth. Stunting that occurred during early childhood may progress into adolescent age.

This study also revealed that girls from educated mothers were less likely stunted than non-educated ones. Those adolescents whose mothers attended secondary and more than secondary education were $47.0 \%$ and $75.0 \%$ less likely stunted respectively as compared to girls whose mothers have no formal education. This finding goes in line with the study conducted in different parts of Ethiopia and other developing countries [14, 22 , $34,36,40-42]$. This is due to the fact that as the level of education of the mother increases, so do her finances as to increased productivity and her contribution to the total family income. This places the family at better nutritional status. In addition, education can also enable the women more likely to make independent decisions that will improve nutrition and health of their children. And to have greater access to household resources that are vital for nutritional status. Moreover educated women are more aware of personal hygiene, promotive and curative health care, the type of food being prepared, distributed and better methods of feeding than that of uneducated or less educated women in a particular family.

The result also showed that adolescent girls from poor families were 2 times more likely to be stunted than adolescent girls from rich one. This finding is similar with the study report in meiso Somali region and with other studies [18, 24, 43, 44]. This may imply that adolescents' nutritional status is just dependant on the socio economic status of the households in which they reside. It causes inadequate quality and quantity of food intake due to unable to purchase variety and preferences of the type of food. It indicated that low socioeconomic status was found to be an important risk factor for stunting. 
Regarding to factors associated with thinness, current study identified that, father educational status was associated thinness. Adolescent girls whose fathers had primary and secondary education level were $52.0 \%$ and $55.0 \%$ less likely thin than those from non-educated fathers. The finding goes in line with other studies from Adama, Mekelle and a study in Beni-Suef Governorate, Egypt[34, 38, 41]. This might be explained that educational attainment of fathers could lead to a higher income there it may imply higher availability of food and household resources. It might be positively associated with high nutritional awareness as well as better caring of their children and parents as the whole.

Similarly, adolescent girls whose mothers completed primary education were $44.0 \%$ less likely to be thin as compared to those who did not have formal education. This study is in agreement with the studies conducted in Adama and Adwa, Ethiopia and Assam, India [22, 34, 36]. This might be because when the level of education of the mother is low, her decision making power and her contribution to the total family income will be low. This places the family at risk of not meeting their needs including nutritional needs. It may also affects the type of food prepared, distributed including the type of care received by the girls in a particular family.

This study also revealed that the number of meal being eaten per day was significantly associated with thinness. Adolescent girls who usually eat two and less meals per day were 1.8 times more likely thin as compared to those who usually eat three meals per day. The finding of this study is consistent with the studies done in Adwa, northern Ethiopia, in Bedelle town, southwest Ethiopia and in bale zone, southeast Ethiopia [5, 22, 25]. This might be because skipping of meals leading to inadequate dietary intake. Adolescence period has the fastest growth and the nutritional requirements are increased to promote this growth spurt. Therefore, in addition to the increased nutritional demand during adolescent period, skipping of meals leads to being thin.

Although the study is first of its kind in the stated area, the author acknowledges some limitations in this study. Some variables such as food security were not included. Data on behavioural and feeding habit may be affected by social desirability bias but during data collection adequate information was given to participants about the importance and confidentiality of information to minimize the bias. Other limitation of this study was that this study was conducted in rural and do not generalize to urban adolescent girl population. The measurement errors could be another possible limitation but standardization of measurements/instruments was done on daily bases.

Adolescence in girls is the most critical period but they are often thought of as healthy, strong and are often not considered within the development agenda as they are not children and not quite adults. According to current study, the prevalence of undernutrition particularly that of stunting which is considered as index of chronic undernutrition indicates that, the poor nutritional status of girls remains uninterrupted throughout their adolescent life. Therefore, targeting adolescence can provide an opportunity to prevent the onset of nutrition related chronic diseases in adults' life and possibly also corrects some nutritional problems originating in the past. So, programs to support adequate nutrition for adolescents could provide an opportunity for healthy transition from childhood to adulthood and could be an important step towards breaking the vicious cycle of intergenerational malnutrition.

\section{Conclusion}

Undernutrition in terms of stunting and thinness among adolescent girls was prevalent problem in the study area. According to the study, being in older adolescent period, educational status of mother, mothers' occupation, and wealth index were significantly associated with stunting among the respondents. Educational status of father, educational status of mother and frequency of meal being eaten per day were significantly associated with thinness among adolescent girls. The prevalence of both stunting and thinness was increasing with increasing age of girls especially in older adolescence. Therefore, routine screening, assessment, counselling and monitoring of adolescent girls' nutritional status at community level and implementing evidence based community nutrition programs are important steps towards alleviating the problem and could provide an opportunity for healthy transition from childhood to adulthood and could be an important step in breaking the intergenerational cycle of malnutrition. Educating parents of adolescent girls at all levels is a useful step in reducing the prevalence of stunting and thinness among adolescent girls.

Recognizing the intergenerational effect of malnutrition and high prevalence of adolescent undernutrition in the study communities, there is a clear need to give due attention to adolescent nutrition. Further research should be considering adolescents from both urban and rural and incorporating additional nutritional assessment methods. There is a clear need to conduct carefully designed longitudinal study to definitively answer the reasons for poor growth throughout the adolescence to understand the intergenerational effect of malnutrition in the study community. Strategies addressing the nutritional status of girls are needed in addition to the conventional approach of providing services to pregnant and lactating women.

\section{List of abbreviations/acronyms}

AOR Adjusted Odds Ratio




$\begin{array}{ll}\text { BMI } & \text { Body Mass Index } \\ \text { BAZ } & \text { Body Mass Index-for-age Z-score } \\ \text { CDC } & \text { Center for Disease prevention and Control } \\ \text { CHIS } & \text { Community Health Information System } \\ \text { CI } & \text { Confidence Interval } \\ \text { COR } & \text { Crude Odds Ratio } \\ \text { HAZ } & \text { Height for-Age Z-scores } \\ \text { OR } & \text { Odds Ratio } \\ \text { PCA } & \text { Principal Component Analysis } \\ \text { SPSS } & \text { Statistical Packages for Social Sciences } \\ \text { TEM } & \text { Technical Error Measurement } \\ \text { VIF } & \text { Variance Inflation Factor }\end{array}$

\section{Ethics approval and consent for participation}

Ethical clearance was obtained from Wolaita Sodo University Ethical Review Committee (ERC) and official letters were obtained from School of public health, Wolaiata Sodo University. The purpose of the study was explained by the data collectors to the study participants and verbal consent and assent was secured from each participant and from their parents or guardians for those ages less than 18 years. Confidentiality of the information was maintained at all levels by preventing the data from being accessed by any other third party.

\section{Availability of data and materials}

The datasets is available and the corresponding author will present on reasonable request.

\section{Competing interests}

The authors declare that they have no competing interests.

\section{Funding}

The authors of this research would like to declare that this research was conducted by a financial support obtained from NORHED-SENUPH (Norwegian Agency for Development Cooperation-South Ethiopia Network Universities in Public health).

\section{Authors' contributions}

DD designed the study, coordinated data collection, performed analysis and interpretation of data and drafted the manuscript. AA conceived the idea, comments on the manuscript and critically reviewed the final manuscript before sending for review and possible publication. TT conceived the idea and helped in the data collection instrument development. All authors have read and approved the final manuscript.

\section{Acknowledgments}

We would like to thank the study participants, data collectors and supervisors for their great contribution during for the success of this study. The authors are also grateful to Wolaita Sodo University and all bodies that gave permission and cooperation to conduct this study.

\section{References}

1. Yoseph Gebreyohannes, S.S., Balem Demtsu, Gessessew Bugssa, Nutritional status of adolescents in selected governmentand private secondary schools of Addis Ababa, Ethiopia. International Journal of Nutrition and Food Sciences, 2014. 3(6).

2. $\quad$ Kedir Teji, Y.D., Tesfaye Assebe, Meyrema Abdo, Anaemia and nutritional status of adolescent girls in Babile District, Eastern Ethiopia. Pan African Medical Journal, 2016. 42.

3. Central Statistical Agency Addis Ababa, E.I.I., Ethiopia Demographic and Health Survey. 2011.

4. Weres ZG, Y.H., Miruts KB, Gesesew HA, and Woldehymanot TE, Assessment of Adolescents' Under Nutrition Level among School Students in Eastern Tigray, Ethiopia: A Cross-Sectional Study Journal of Nutrition and Food Sciences, 2015. 5:5.

5. Tsedeke Wolde, W.A., Dagnie Mekonnin, Firew Yitayin,Fedasa Abu,Fufa Dufera Tadesse Birhanu, Eyasu Ejeta, Nutritional Status of Adolescent Girls Living in Southwest of Ethiopia. Food Science and Quality Management, 2014. 34.

6. Tolessa Dekeba Damie, M.W., Aderajew Nigussie Teklehaymanot, Nutritional status and associated factors among school adolescent in Chiro Town, West Hararge, Ethiopia. Gaziantep Medical Journal, 2015. 21(1).

7. Dr.A.Shravan Kumar, D.A.N.S., Dr.M.Sreedhar, Nutritional status of Adolescent girls of urban slums 
of Hyderabad. Indian Journal of Basic and Applied Medical Research, 2014. 4: p. 457-461.

8. Saxena, G., Study on Nutritional Status of Adolescent Girls in Karnal District International Journal of Education and Science Research Review, 2015. 2.

9. Md. Jashim Uddin, S.K.N.a.S.K.S., Anthropometric Assessment of Nutritional Status of Adolescents in Rural School of Unokoti District of Tripura, North-East India. jornal of Anthropologist, 2015. 19(1): p. 277-284.

10. Sarah E. Cusick, a.A.E.K., BA, Determinants of Undernutrition and Overnutrition among Adolescents in Developing Countries. Adolesc Med State Art Rev 2012. 23(3): p. 440-456.

11. N Otis, J.N.-P.a.L.C., Predictors of Undernutrition and Stunting Among Adolescents in Tanzania: a Rural/Urban Comparison. FASEB Journal, 2015. 29: p. 579.16.

12. TM Berheto, W.M., A Argaw, Urban-rural disparities in the nutritional status of adolescent girls in the Mizan district, southwestern Ethiopia. The International ElectronicJournal of Rural and remote health 2015. 15: 2687.

13. SaxenaMD, Y.S.M.a.V., Nutritional Status in Rural Adolescent Girls Residing at Hills of Garhwal in India (2009). Internet Journal of Medical Update, 2011. 6(2).

14. Idowu O. Senbanjo, K.A.O., Olumuyiwa O. Odusanya, and Olisamedua F. Njokanma, Prevalence of and Risk factors for Stunting among School Children and Adolescents in Abeokuta, Southwest Nigeria. Jornal of Health and population nutrition, 2011. 29(4).

15. Institute, E.H.a.N.R., Nutrition Baseline Survey Report for the National Nutrition Program of Ethiopia. Unpublished document, 2009/10.

16. World Food Programme WFP, n.w.o., Preventing Chronic Malnutrition Nutrition at the World Food Programme. 2014.

17. Firehiwot Mesfin, Y.B., Alemayehu Worku, Prevalence and associated factors of stunting among primary school children in Eastern Ethiopia. Journal of Nutrition and Dietary Supplements 2015. 7.

18. Louise H. Dekker, M.M.-P., Constanza Marín, Ana Baylin,and Eduardo Villamor, Stunting associated with poor socioeconomic and maternal nutrition status and respiratory morbidity in Colombian schoolchildren. Food and Nutrition Bulletin, 2010. 31.

19. Yohannes Adama Melaku, G.A.Z., Tiffany K. Gill, Robert J. Adams and Zumin Shi, Prevalence and factors associated with stunting and thinness among adolescent students in Northern Ethiopia: a comparison to World Health Organization standards. Archives of PublicHealth Journal, 2015. 73:44.

20. Afework Mulugeta, F.H., Barbara Stoecker, Gideon Kruseman3, Vincent Linderhof, Zenebe Abraha,Mekonen Yohannes and Girmay G. Samuel, Nutritional Status of Adolescent Girls from Rural Communities of Tigray, Northern Ethiopia. Ethiopian Journal of Health Development, 2009. 23(1).

21. Dhingra, R., An Assessment of Health Status of Adolescent Gujjar Tribal Girls of Jammu District. 2011. 9(2): p. 133-138

22. Tsgehana Gebregyorgis, T.T., and Azeb Atenafu, Prevalence of Thinness and Stunting and Associated Factors among Adolescent School Girls in Adwa Town, North Ethiopia. International Journal of Food Science, 2016.

23. VarunGaiki, V.W., Nutritional status of Adolescent girls from selected Rural area of A district from Central India. Innovative Journal of Medical and Health Science, 2014. 4 p. 90-92.

24. Abdulkadir Abdella Awel, T.B.L.a.H.J.H., Nutritional status and associated factors among primary school adolescents of pastoral and agropastoral communities, Mieso Woreda, Somali Region,Ethiopia: A comparative cross-sectional study. Journal of Public Health and Epidemiology, 2016. 8(11): p. 297310 .

25. Ahmed Yasin Mohammed, T.B.T., Nutritional Status and Associated Risk Factors among Adolescent Girls in Agarfa High School, Bale Zone, OromiaRegion, South East Ethiopia. International Journal of Nutrition and Food Sciences, 2015. 4(4)

26. Craig Hadley, T.B., David Lindstrom, and Fasil Tessema, The Forgotten Population? Youth,Food in security, and Rising Prices:Implications for the Global food Crisis. 2009 32(1): 77-91.

27. Central Statistical Agency Addis Ababa, E., EMDHS Ethiopian Mini Demographic and Health Survey. 2014.

28. Lohman, T.G., A.F. Roche, and R. Martore Anthropometric standardization reference manual.Champaign: Human Kinetics Books. 1991.

29. World Health Organization, G., Switzerland, WHO, AnthroPlus for Personal ComputersManual: Software for Assessing Growth of theWorld's Children and adolescents 2009.

30. Molla Mesele Wassie, A.A.G., Melkie Edris Yesuf, Getu Degu Alene, Adamu Belay and Tibebu Moges, Predictors of nutritional status of Ethiopian adolescent girls: a community based cross sectional study. Journal of Biomedical Center, 2015. 1:20.

31. Sweta Singh, S.K.K., Assessment of nutritional status of adolescent girls in rural area of district 
varanasi. Indian Journal of Research, 2012. 6: p. 30-4.

32. H.R. Shivaramakrishna, A.V.D.a.M.S., Nutritional Status of Adolescent Girls in Rural Area of Kolar District: A Cross-Sectional Study. A US National Library of Medicine enlisted journal, 2011 4(3) p. $243-246$.

33. B, S., Anthropometrically Determined Undernutrition among the Adolescent Girls in Kathmandu Valley. Kathmandu University medical journal 2015. 51(3).

34. Roba KT, A.M.a.W.T., Nutritional Status and Its Associated Factors among School Adolescent Girls in Adama City, Central Ethiopia. Journal of Nutrition \& Food Sciences, 2016.

35. Shahid A, S.F.R., Bhatti M.A, Ahmed M., Khan M.W, Assessment of Nutritional Status of Adolescent College Girls at Rawalpindi. journal of ommunity Medicine Department, 2009. 15.

36. Himashree Bhattacharyya, A.B., Nutritional Status and factors affecting Nutrition among Adolescent Girls in Urban Slums of Dibrugarh,Assam. National Journal of Community Medicine, 2013. 4.

37. T, A.K., Nutritional Status of Adolescent Girls in Rural Tamilnadu. Nat.J.Res.Com.Med, 2012. 1(1): p. $1-60$.

38. Hadush Gebremariam, O.S., Huruy Assefa, Assessment of nutritional status and associated factors among school going adolescents of Mekelle City, Northern Ethiopia. International Journal of Nutrition \&Food Sciences, 2015. 4(1).

39. Rani, N.R.a.V., Assessment of Nutritional Status of School Going Adolescents in Fatehabad District of Haryana. Indian Journal of Nutrition, 2016. 3.

40. Amitava Pala, A.K.P., Arunanshu Sinhac,Prakash C. Dharaa, Prevalence of undernutrition and associated factors: A cross-sectional study among rural adolescents in West Bengal, India. International Journal of Pediatrics and Adolescent Medicine, 2016.

41. Shaimaa B. Abdelaziz, M.R.L.Y., Amal S. Sedrak,John Rene Labib, Nutritional Status and Dietary Habits of School Children in Beni-Suef Governorate, Egypt. Journal of Food and Nutrition Sciences, 2015. 6: p. 54-63.

42. Melody Seb Rengma, K.B., Nitish Mondal, Socio-economic and demographic correlates of stunting among adolescents of Assam, North-east India. Journal of Anthropological review, 2016. 79(4).

43. Bwalya, B.B., Nutritional Status Among Female adolescents aged (15 - 19 years) in Zambia: Why it Matters. Horizon Journal of Medicine and Medical Sciences, 2015. 1(1) p. 001-007.

44. Huruy Assefa, T.B., Legesse Negash, Socio-demographic factors associated with underweight and stunting among adolescents in Ethiopia. Pan African Medical Journal, 2015. 20. 